\title{
Influence of SMA reinforcement on the impact resistance of GFRP composite laminates under different temperatures
}

\author{
K PAZHANIVEL ${ }^{1, *}$, G B BHASKAR ${ }^{2}$, A ELAYAPERUMAL ${ }^{3}$, P ANANDAN $^{4}$ and \\ S ARUNACHALAM ${ }^{5}$ \\ ${ }^{1}$ Department of Mechanical Engineering, Thiruvalluvar College of Engineering and Technology, Vandavasi 604505, India \\ ${ }^{2}$ Department of Production Technology, MIT Campus, Anna University, Chennai 600044, India \\ ${ }^{3}$ Department of Mechanical Engineering, Anna University, Chennai 600025, India. \\ ${ }^{4} \mathrm{PG}$ and Research Department of Physics, Thiru Kolanjiappar Governement Arts College, Vridhachalam 606001, India \\ ${ }^{5}$ Department of Civil Engineering, Thiruvalluvar College of Engineering and Technology, Vandavasi 604505, India
}

MS received 12 July 2015; accepted 18 December 2015

\begin{abstract}
Plain glass fibre-reinforced polymeric (GFRP) laminates and GFRP reinforced with randomly oriented short strips of shape memory alloy (SMA) were prepared by hand lay-up method. The SMA strip reinforcement was placed at $0.75 \times$ thickness of the laminate with weight fractions of 2,4 and $6 \%$. The specimens were exposed to drop weight impact test and the experiments were conducted at a constant impact velocity of $2.80 \mathrm{~m} \mathrm{~s}^{-1}$ with different test temperatures such as 303,333 and $363 \mathrm{~K}$. The impact damage area was evaluated using lighting technique and fracture response was analysed using scanning electron microscopic (SEM) images. Absorption of impact energy and damage area due to low velocity impact were calculated. It was observed that with the higher temperature, the SMA/GFRP laminates exhibit marginally-enhanced damage resistance compared to the plain GFRP laminates. Also, addition of SMA reinforcement was not contributing much to the impact resistance at higher temperature.
\end{abstract}

Keywords. GFRP laminates; shape memory alloy; low velocity impact; impact resistance; SEM.

\section{Introduction}

Composite materials offer numerous advantages over conventional materials owing to their superior specific strength and stiffness. The use of composite materials has become increasingly common in a wide range of structural components and engineering applications including high speed train, aerospace, marine and sports engineering [1]. Many such applications involve components subjected to various loadings causing damage, degradation of material properties and even premature failure of the structure [2]. Currently, there is an increased interest in the application of composite materials with embedded shape memory alloy (SMA laminates) to control or relax the damage in composite materials $[3,4]$. An important reliability factor in design of such composites is the response to impact loading. Composite structures in general are susceptible to a wide range of damages and defects such as delamination, fibre breakage, fibre pullout and matrix crazing which are produced during fabrication as well as service [5]. This calls for determining reasonable ways to control such damages, without compromising the structural integrity. Normally, heterogeneous composites exhibit better impact resistance owing to enhanced structural damping compared to homogeneous metallic material (barring the dual phase material). One possible way to

*Author for correspondence (rkvel2003@gmail.com) increase impact (damage) resistance of composite structure is by embedding SMA wires into composite structures. SMA wires embedded within the layers of composite structures can enhance their resistance to low-velocity impact, which is, however, greatly influenced by the constituent materials and their lay-ups as well [5]. Hence, it is necessary to understand the impact damage characteristics when SMA wires are embedded into composite laminates. Further structures are also subjected to severe environment conditions such as high temperature. The study of impact response of composite materials subjected to environmental conditions other than ambient is more realistic and researches [6-8] have investigated the effect of environmental conditions on impact damage phenomenon of composite materials.

Study on the influence of temperature and moisture on the impact resistance of an epoxy/graphite composite material has found that only elevated temperatures/moisture had a significant effect on damage initiation energy [6]. Bibo et al [7] have shown that temperature can alter the nature and extent of impact induced damages. Ibekwe et al [8] have experimentally studied the impact and residual load carrying capacity of unidirectional and cross-ply laminates at low temperatures. Kang et al [9] have experimentally studied the damage behaviour of glass/epoxy laminates with embedded SMA wire subjected to low-velocity impact under low temperature. Metin Sayer et al [10] have studied and reported the impact behaviour of hybrid composites (carbon-glass 
fibre/epoxy), subjected to both low-velocity impact and various temperatures ranging from -20 to $60^{\circ} \mathrm{C}$. The effect of temperature on maximum energy, maximum deflection, maximum impact force, ductility and compression after impact was studied at different low impact energy levels $(8,15$ and $25 \mathrm{~J}$ ) with the temperature range of $50-120^{\circ} \mathrm{C}$. The effect of temperature in the range of $50-120^{\circ} \mathrm{C}$ on impact response at different energy levels such as impact force, energy has been reported. Possible absorption of moisture at change of state of polymer to rubbery/leathery depending on the temperature can influence dynamic response/impact resistance [11]. The impact behaviour of glass fibre-reinforced polyester (GFRP) was experimentally investigated using notched Izod impact test specimen and the effect of fibreorientation, fibre volume fraction, test temperature and exposure time to test temperature on failure mechanism of the GFRP composites have been reported [12]. The shape memory characteristics of cold-worked TiNiNb alloys were investigated for developing shape memory alloy/carbon fibre-reinforced plastics hybrid composites for damage suppression at ambient temperature [13]. The effect of shape memory alloy (SMA) on damage behaviour and residual properties of composite laminates subjected to low-velocity impact at low temperatures has been investigated [14]. The effects of temperature and thermal residual stresses on the impact behaviour and damage of glass/epoxy laminated composites were investigated. Also, the impact analysis on the laminated composites was performed at the different ranges of impact energies under different temperatures. The specific energy values and impact parameters were obtained and compared for each type of specimens and temperatures [15]. Impact energy absorption and damage area due to low-velocity impact on the GFRP composites with SS wire reinforced GFRP composites were calculated, and efficiency of absorption was compared with respect to impact velocity and pitch distance of the SS wires [16]. Tensile and instrumented impact testings were carried out to evaluate improvements in mechanical properties and toughness of the composites. Appreciable improvement was observed in damping, tensile and impact properties of the polymer matrix due to reinforcement with superelastic SMA fibres, highlighting the advantages of their use in polymer composites [17]. The impact damage resistance properties of SMA stitched glass/epoxy composites after low-velocity impact are experimentally and theoretically studied. The results showed that the tensile strength of composite plates increased and the number of translaminar cracks decreased after being stitched by SMA wires. Theoretical study also proves that the delamination energy of composite plates after stitching with superelastic SMA wires is smaller than that of an unstitched composite plate because of the energy absorbed by the SMA wires [18]. The vibrational characteristics of SMA composites can be improved by the addition of small amounts of SMA short fibres. The addition of $3.5 \mathrm{wt} \%$ of SMA short fibre content to epoxy resin resulted in the maximum increment in both natural frequency and storage modulus [19]. Epoxy resin composites filled with Ti-Ni alloy short fibres and particles were fabricated and their mechanical properties were investigated. Owing to the addition of SMA fillers, the flexural rigidity of SMA/epoxy composites increases; especially, the storage modulus increases remarkably with increasing filler content in the high temperature region [3]. This is attributable to transformation to austenitic phase facilitating better dynamic characteristics.

In this study, SMA strip in the form of short fibre has been chosen as the reinforcing material to evaluate the impact strength of the SMA/GFRP laminates. Assessment on impact energy absorption and damage area was carried out for both plain GFRP composites and SMA wire-reinforced GFRP composites; also influence of wt $\%$ of SMA on impact response under different temperatures was evaluated. The detailed discussion on the influence of SMA wire reinforcement with different weight contents regarding the impact response is presented in this paper.

\section{Experimental}

\subsection{Materials}

The SMAs used in the present study are Ti-Ni alloy (nitinol) flat wire ( $\mathrm{Ti}: \mathrm{Ni}=50: 50)$ produced by Memry, SAES Group Company, USA. The dimensions of SMA short strips are; length of 2-3 mm, width of $1.35 \mathrm{~mm}$, thickness of $0.292 \mathrm{~mm}$ and the length of the specimen is $130 \mathrm{~mm}$. Other elements can be added to adjust or tune the material properties. Nitinol exhibits unique thermo-mechanical behaviour. The two terms used to describe this behaviour are shape memory effect and super elasticity. The phase transformation temperature for austenite of Ti-Ni alloy is about $72^{\circ} \mathrm{C}$. The matrix polymer was LY556 epoxy resin, and the hardening agent was HY951. The glass transition temperature $\left(T_{\mathrm{g}}\right)$ is around $140^{\circ} \mathrm{C}$. The fibre used as reinforcement was $\mathrm{S}$-type glass fibre of $600 \mathrm{gsm}$.

\subsection{Specimen fabrication}

Plain and SMA short strips reinforced laminates were made by hand lay-up method and cured at room temperature for about 24 h. A layer of epoxy araldite resin (LY556) with hardener (HY951) in the ratio of 10: 1 was applied on the mould surface. The stacking sequence consists of four layers of cross-ply $[(0 / 90)]_{4}$ yielding a total thickness of 3 $( \pm 0.1) \mathrm{mm}$. Also, four layers of cross-ply glass fibre mat were used and SMA short fibres were poured at 3/4th depth $(t)$ of the laminates with random orientation. Sufficient care was taken to ensure complete wetting of the fibres for effective bonding and to remove the entrapped air and excess resin. Due to low cure shrinkage, SMA/GFRP laminates are stable and free from internal stress. Laminates were properly cut for dimensions as per the ASTM standard. The weight content of SMA short fibres was represented by 2, 4, and $6 \mathrm{wt} \%$, respectively. Laminates were properly cut for dimensions as per the ASTM standard (D7192) for impact test $(100 \mathrm{~mm} \times 100 \mathrm{~mm})$. Typical illustration of the test specimen is shown in figure 1 . To evaluate the impact strength 


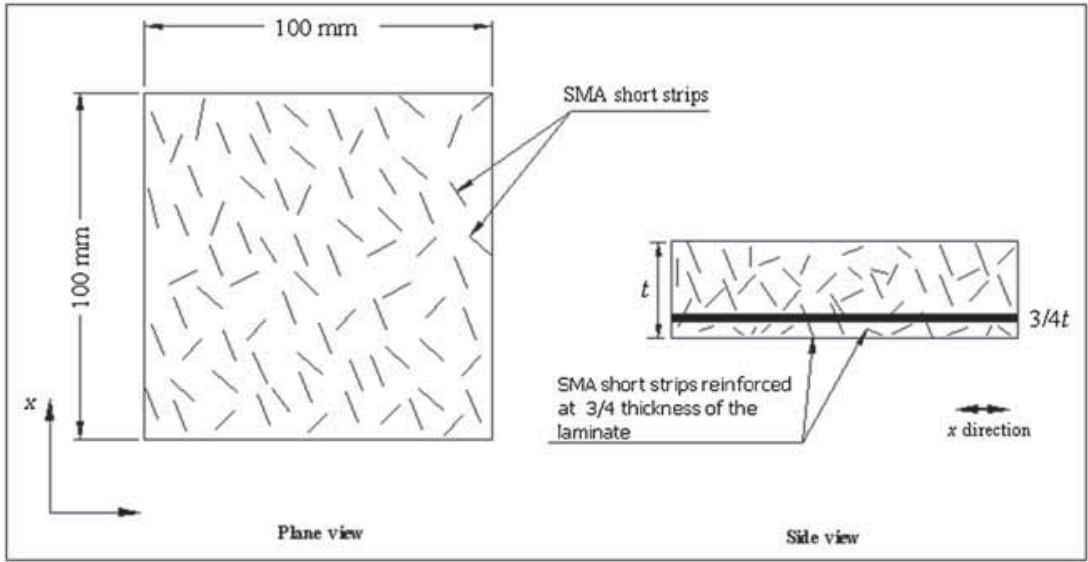

Figure 1. Illustration of impact specimen dimensions explains the reinforcement position of SMA short strips.

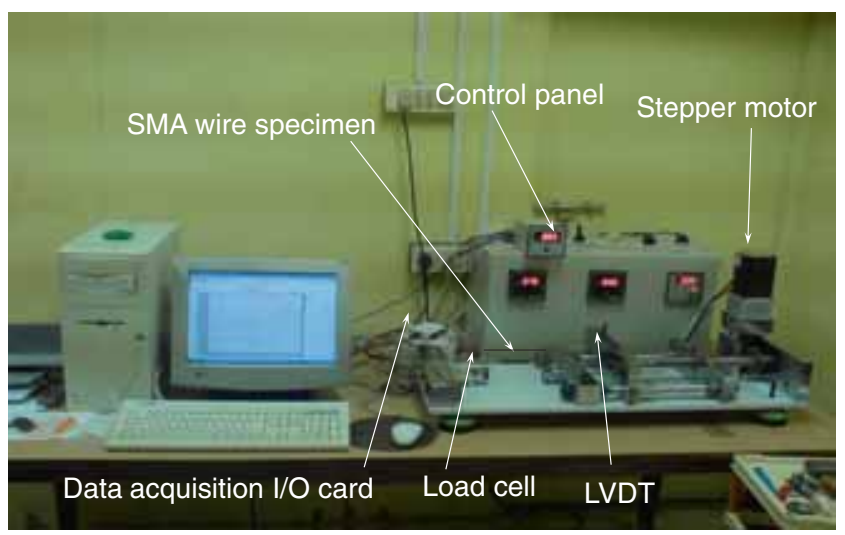

Figure 2. Computerized tensile test setup testing SMA wires/ strips.

of the material, three types of specimens were made with different SMA weight percentages.

\subsection{Tensile test setup}

Experimental results were obtained using Ti-Ni specimens subjected to tensile testing with quasi-static strain rate. The experimental setup of the adopted instrumentation is shown in figure 2. It is possible to see load cell, LVDT, specimen fixtures, stepper motor and the system used for data acquisition and processing. The experiments were carried out in SMA strips to evaluate its mechanical properties which are used as additional reinforcement in the GFRP composites.

\subsection{Drop weight impact testing}

Specimens of plain GFRP composites and with SMA strips reinforced at $0.75 \times$ thickness $(0.75 t)$ of the laminate with 2 , 4 and $6 \mathrm{wt} \%$ of SMA addition were subjected to drop weight impact at constant velocity of $2.80 \mathrm{~m} \mathrm{~s}^{-1}$ for three different temperatures of 303,333 and $363 \mathrm{~K}$ using a CEAST Fractovis drop impact tower fitted with an anvil of diameter
$76 \mathrm{~mm}$, which was clamped on the plates using a pressurized system (clamping force of $1000 \mathrm{~N}$ ). The detailed explanation of the impact testing setup is discussed in our earlier report [16] and the photograph of the drop weight impact setup is shown in figure 3 . This clamping on a circular periphery is to ensure proper positioning of the specimen and to prevent any lateral movement during impact and the clamping force of $1000 \mathrm{~N}$ over the periphery of $76 \mathrm{~mm}$ diameter circle, will not inflict any damage on the structure. A hemispherical indenter with mass of $10 \mathrm{~kg}$ and diameter of $12.7 \mathrm{~mm}$ was used as impactor. The specimens were subjected to low-velocity impact. The response was evaluated in terms of force-time plot using a piezo-dynamo meter. For this, a sensitive data acquisition system and a load transducer were connected to the impactor. The resistance of the composite to the impact of the falling weight was monitored by suitable telemetry attached to the falling weight. Graphical plots were generated using the data collected from the data acquisition system. From the acquired data, parameter like peak load, deflection at peak load and absorbed energy were evaluated. Three different temperature ranges were maintained for all test samples using a thermal chamber. The damage area was calculated by lighting technique and the fibre/matrix damages were analysed through scanning electron microscope (SEM).

\section{Results and discussion}

\subsection{Mechanical characterization of SMA}

Shape memory alloy (SMA) is a specific material which can remember and return to its original shape after considerable deformation. This function of shape memory alloys results from the thermo-elastic martensitic transformation. The loading and unloading characterization of shape memory alloy is illustrated in figure $4 \mathrm{a}$. The dip/stress hold in the loading path could be attributed to pseudo-elastic effect of the SMA wire; this wire induces interfacial stress in the composite; resulting in rapid relaxation during unloading 


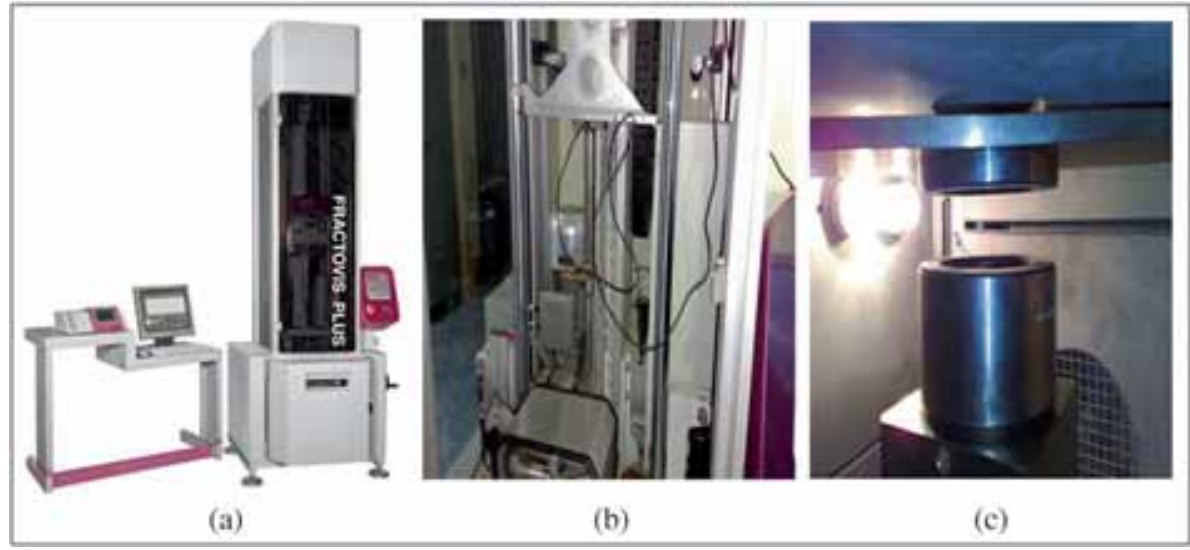

Figure 3. Photographs of (a) impact testing machine, (b) striker view and (c) specimen holder.
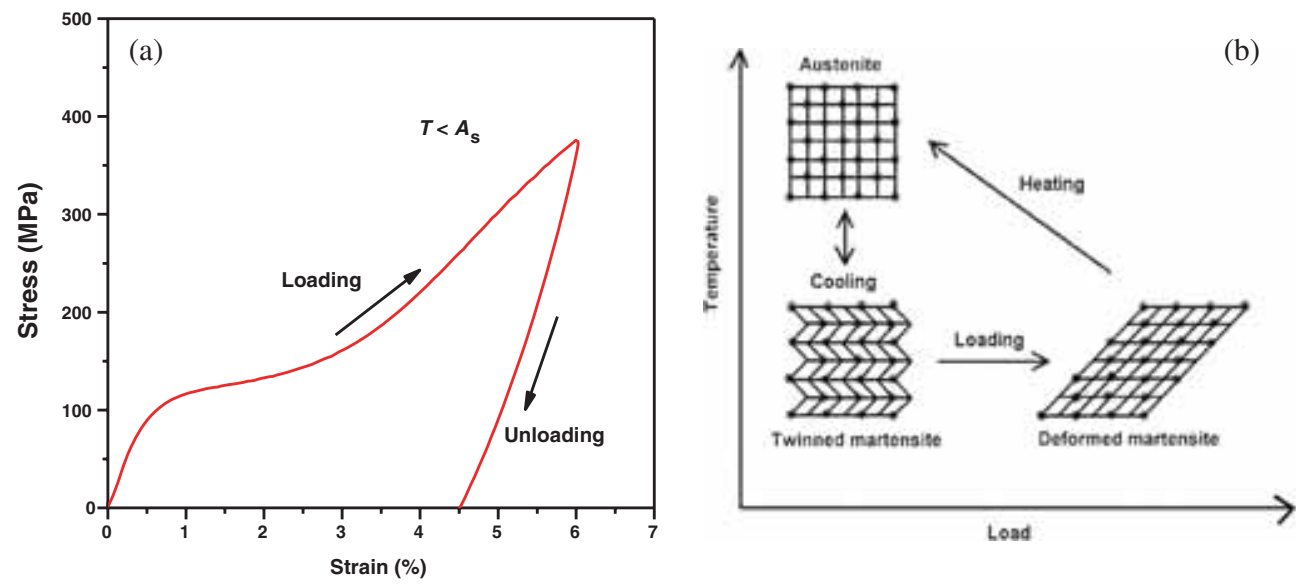

Figure 4. (a) Stress-strain curve of shape memory effect and (b) schematic of shape memory effect.

accounting for the hysteresis effect/strain energy absorption. The schematic micro-mechanism of the SME is shown in figure $3 \mathrm{~b} . M_{\mathrm{s}}, M_{\mathrm{f}}, A_{\mathrm{s}}$ and $A_{\mathrm{f}}$ are indications of the starting and finishing temperature of martensitic and austenitic transformation, respectively. The martensite will be produced when the parent austenite phase is cooled below the $M_{\mathrm{s}}$. At this stage, there will be no macro-size change (no volume dilation) because of the coordinately twinned deformation, called self-accommodation. Twinned boundaries will move and disappear when the martensite undergoes extra stress at the temperature below $M_{\mathrm{f}}$, which results in macrodeformation (pseudo-elastic effect). On heating to the $A_{\mathrm{s}}$ temperature, the deformed martensite will resume the original shape of the parent through the reverse transformation from the martensite to the parent austenite phase. The macro-deformation of the matrix due to pseudo-elastic effect can stress the surrounding matrix and consequently influenced the strength of the composite. Shape memory effect describes the process of restoring the original shape of a plastically-deformed sample by heating it. This is a result of a

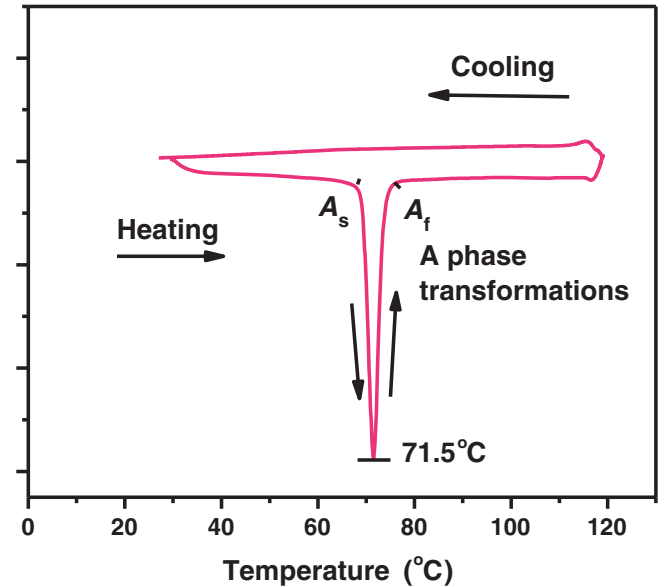

Figure 5. DSC curve of SMA strip shows phase transformation.

crystalline phase change known as thermo-elastic martensitic phase transformation. Below the transformation temperature, nitinol is martensitic. The soft martensitic microstructure is 
characterized by self-accommodating twins, a zigzag like arrangement. Martensite is easily deformed by de-twinning. Heating the material converts the material to its high strength, austenitic condition. The transformation from austenite to martensite (cooling) and the reverse cycle from martensite to austenite (heating) do not occur at the same temperature. There is a hysteresis curve for every nitinol alloy that defines the complete transformation cycle. The shape

(a)

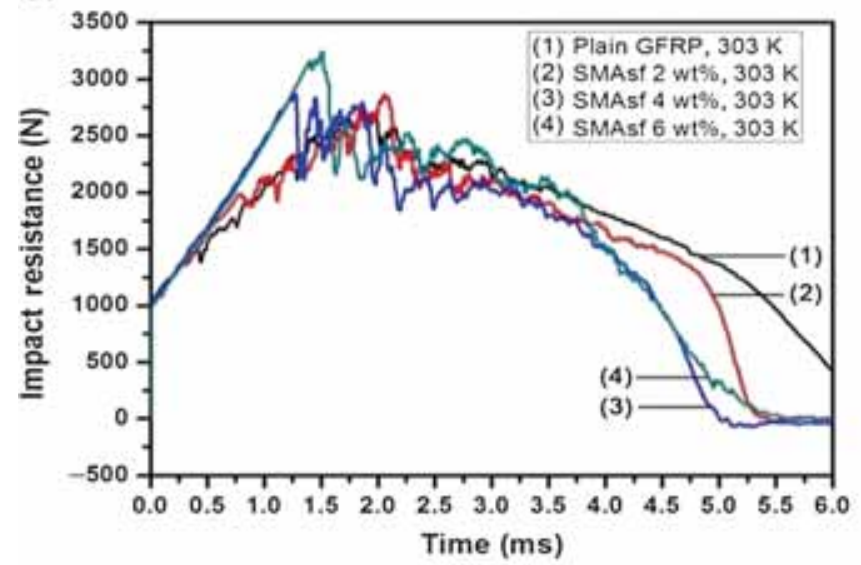

(b)

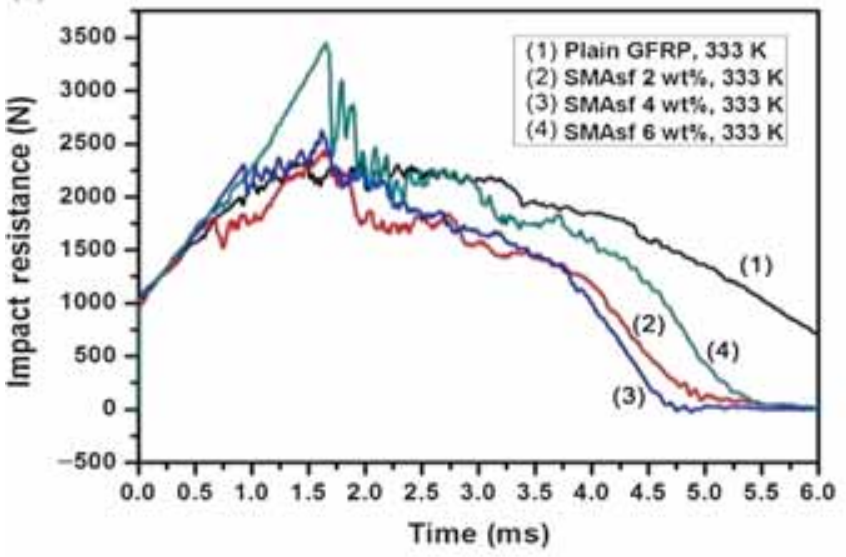

(c)

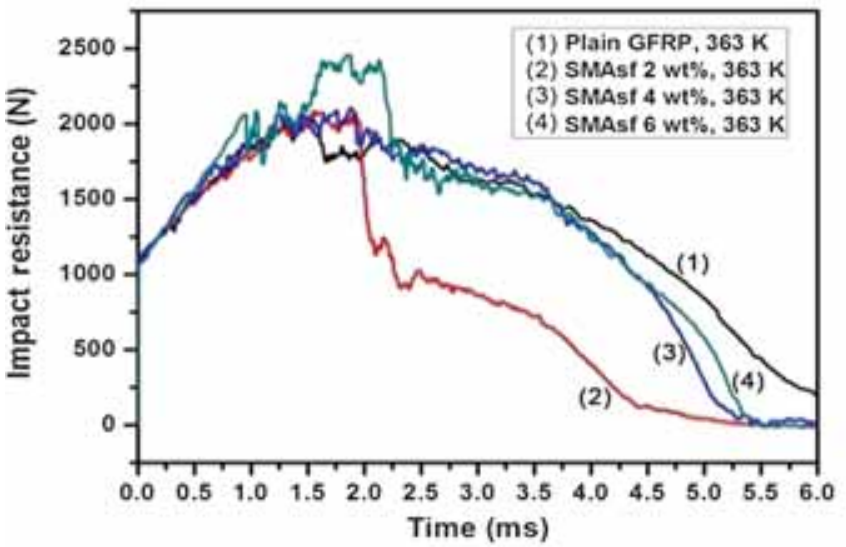

memory effect is repeatable and can typically result in up to $6 \%$ strain recovery.

\subsection{Phase transformations of SMAs}

Shape memory alloys undergo diffusion-less martensitic transformation on cooling below critical temperature, $M_{\mathrm{s}}$, which is dependent on alloy composition, processing

(d)

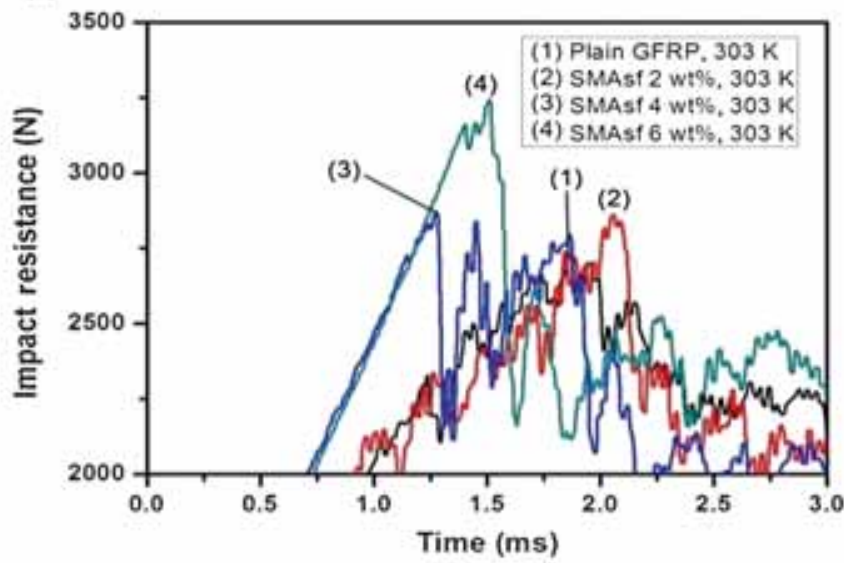

(c)

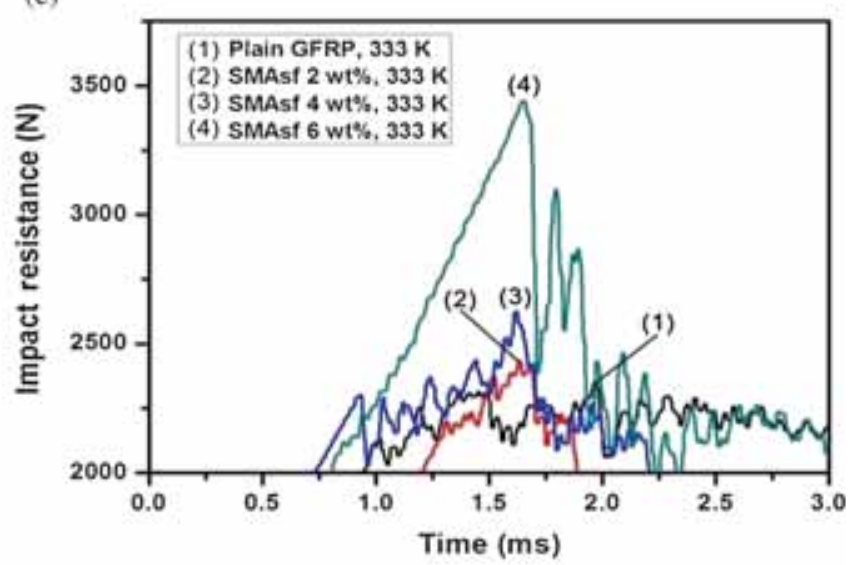

(f)

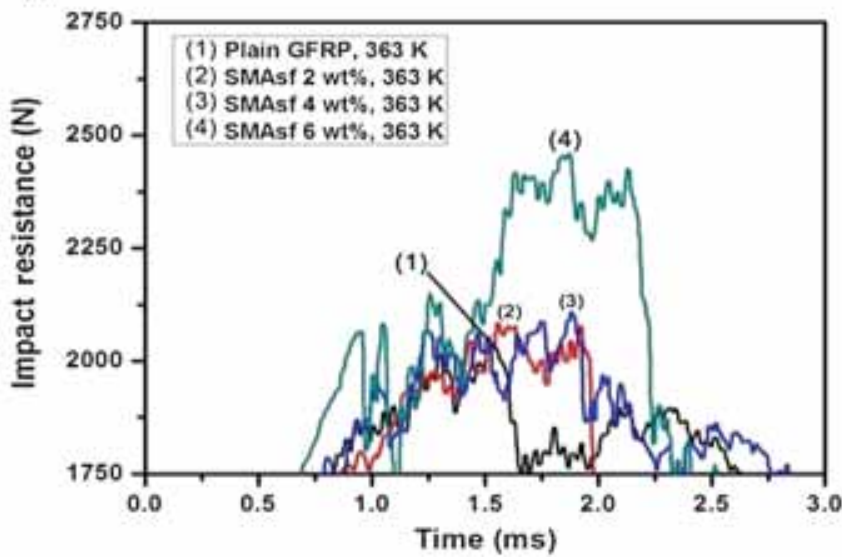

Figure 6. Impact resistance $v$ s. time chart at (a) 303, (b) 333 and (c) $363 \mathrm{~K}$ (asymmetric region of the chart is magnified in d, e and $\mathbf{f}$, respectively). 
procedures and thermal/mechanical treatment conditions. Figure 5 shows the differential scanning calorimetric (DSC) curves demonstrating the hysteresis of the phase transformation in used SMAs. The phase transition of SMAs occurs when the temperature increases. The beginning $\left(A_{\mathrm{s}}\right)$ and end $\left(A_{\mathrm{f}}\right)$ temperatures of the austenite transformation are from about $65-75^{\circ} \mathrm{C}$. In the cooling process, the martensitic phase

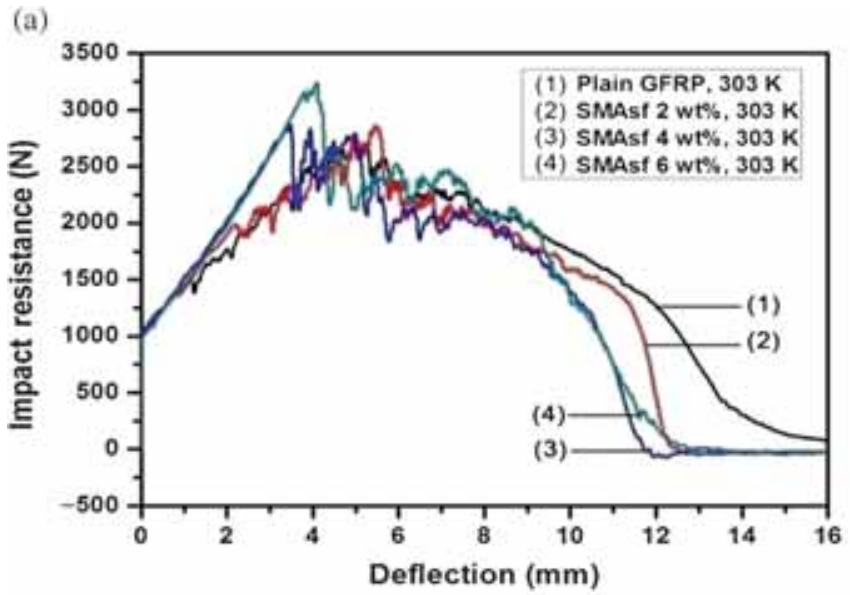

(b)

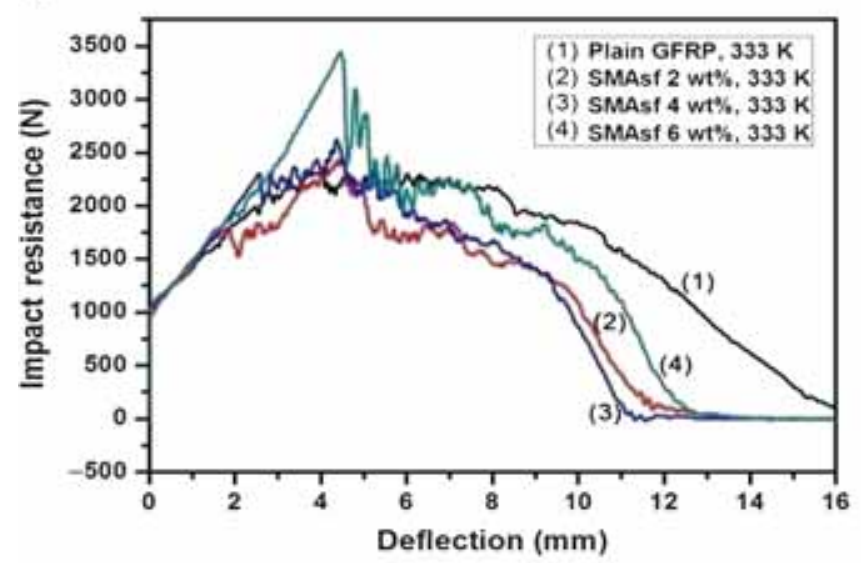

(c)

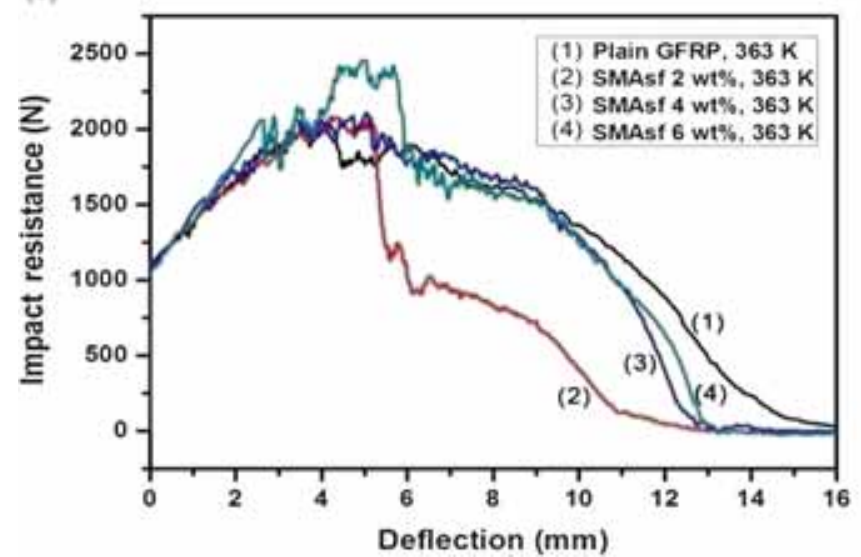

transformation temperature occurs from about $25-5^{\circ} \mathrm{C}$, associated with cell distortion (body centred tetragon). Unlike the case of martensite transformation, austenite transformation is more or less instantaneous within a critical temperature of around $70^{\circ} \mathrm{C}$. Thus, a working environment arround the critical temperature will lead to rapid increase in damage/energy absorption.

(d)

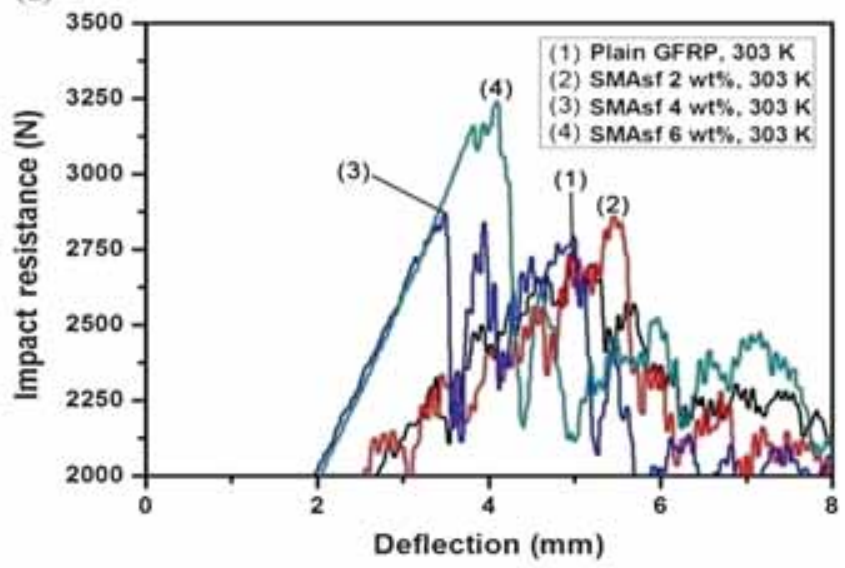

(e)

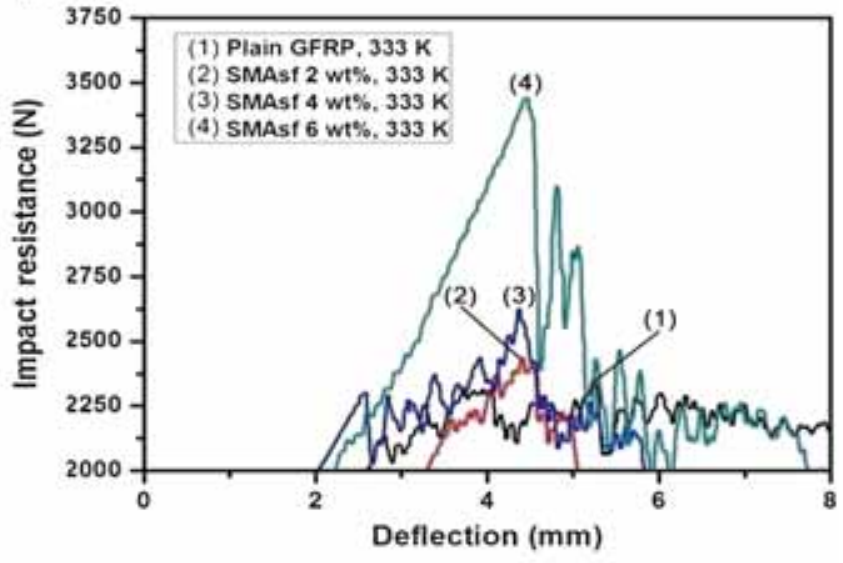

(f)

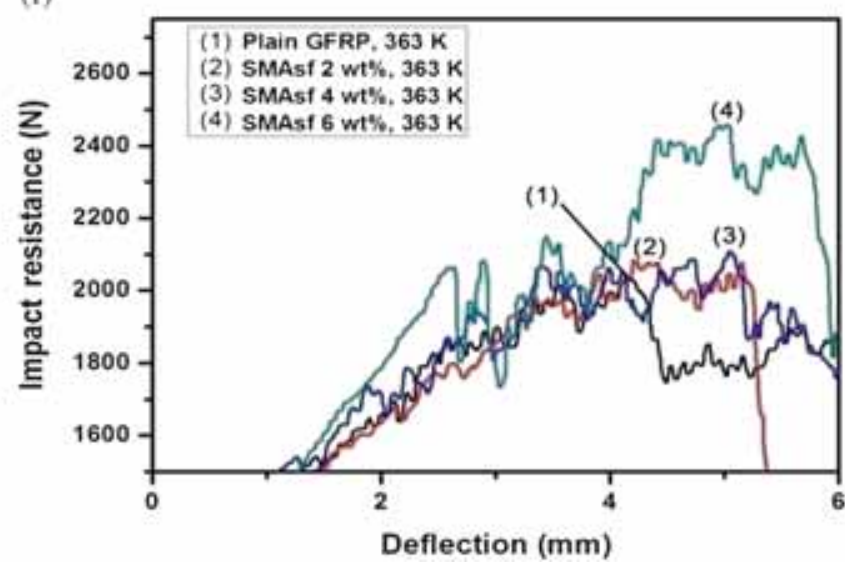

Figure 7. Impact resistance $v$ s. displacement chart at (a) 303, (b) 333 and (c) $363 \mathrm{~K}$ (asymmetric region of the chart is magnified in d, e and $\mathbf{f}$, respectively). 


\subsection{Impact analysis}

3.3a Force vs. time history: During the drop weight impact, the resistance offered by the composite specimen to penetration (impact resistance) is recorded by the telemetry attached to the falling weight in the test setup. The recorded force/impact resistance in Newton (N) and the traverse of the indenter in millisecond (ms) is illustrated in figure 6 . It is observed that up to around $0.5 \mathrm{~ms}$, i.e., mid-section of the composite specimen, the impact resistance is almost unaffected by the presence of the SMA strips (The thickness of the laminate is $3 \mathrm{~mm}$ and the impactor took $1 \mathrm{~ms}$ to travel through the laminate as observed in figure 7 . It can be understood by comparing the figures 6 and 7 that $0.5 \mathrm{~ms}$ is mid-section of the composite specimen.). Beyond $0.5 \mathrm{~ms}$, the penetration of the indenter below the mid-section is associated with tensile strength, resulting in delamination of the composite. It is observed that the composite specimen exhibit a progressive increase in impact resistance up to certain traverse duration of the indenter followed by a drop. Tensile strength of the composite specimen is associated with pseudo-elastic deformation/straining of the SMA in martensite phase, which strengthened the composite and consequently raised the impact resistance. Also, it is observed that the peak impact resistance drops down with reducing weight percentage of the SMA strips. The increased duration of the traverse of the indenter with reducing wt\% of SMA, is attributable to occurrence of deeper elongated fluffed material over the exit of the indenter. Typical time-dependent variation of impact resistance of composite material undergone drop weight impact at $303 \mathrm{~K}$ is shown in figure $6 \mathrm{a}$ and $\mathrm{d}$. As in the case of $303 \mathrm{~K}$ testing temperature, with $333 \mathrm{~K}$ also up to around $0.5 \mathrm{~ms}$, there is no influence of SMA addition on impact resistance as shown in figure $6 \mathrm{~b}$ and e. Barring the case, $6 \mathrm{wt} \%$ addition of SMA, GFRP composite impacted at $333 \mathrm{~K}$, exhibits an overall reduction in impact resistance. However, in the case of the specimens impacted at $363 \mathrm{~K}$ as shown in figure $6 \mathrm{c}$ and $\mathrm{f}$, all the composite specimens exhibit an overall reduction in impact resistance relative to impact with reduced temperature.

3.3b Force vs. deflection (penetration depth): Typical impact force/impact resistance-deflection (penetration
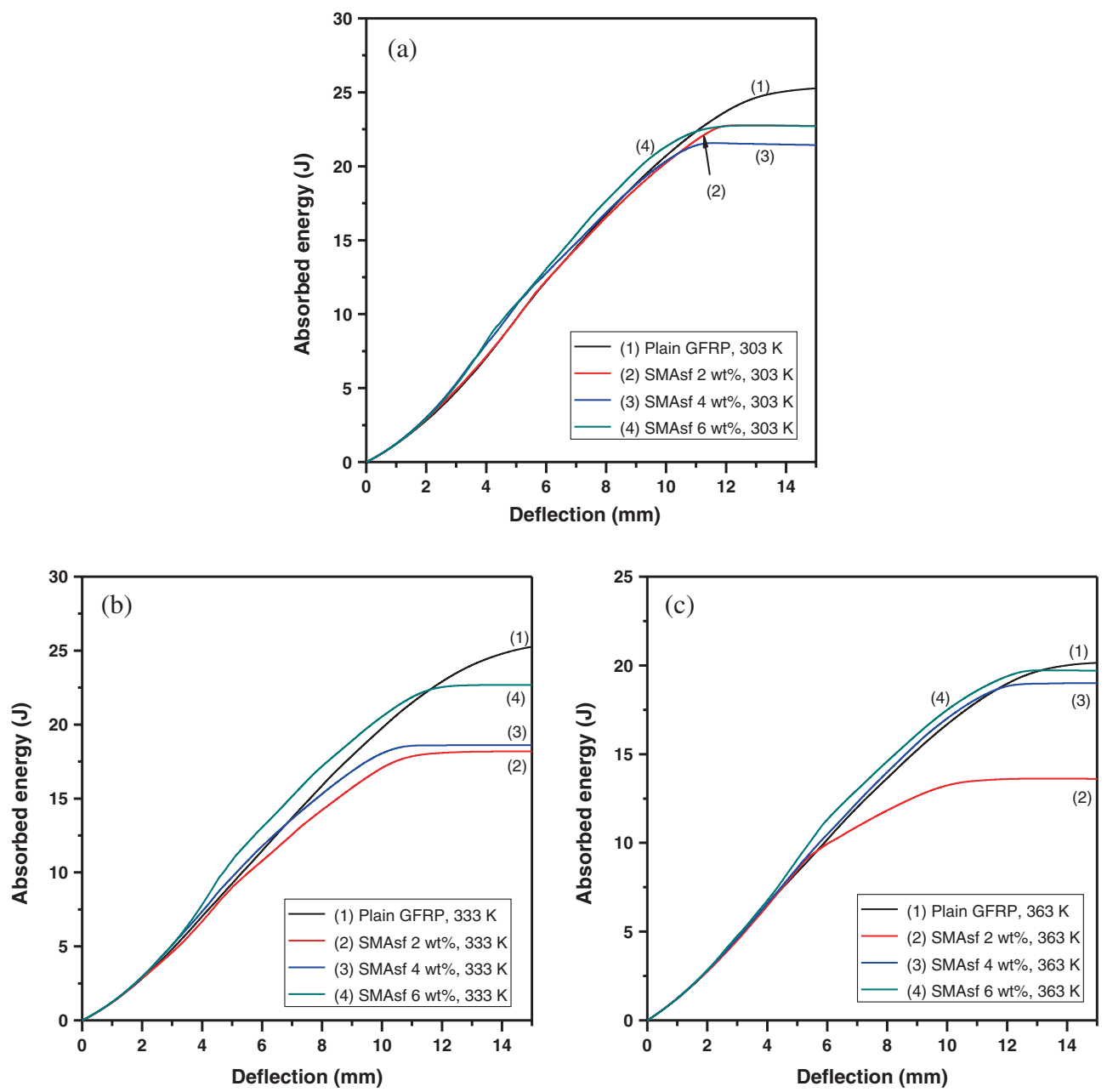

Figure 8. Absorbed energy vs. deflection chart shows the variation of energy absorbed with indenter traverse. 
depth) characteristics are shown in figure 7. It is observed that up to around $1.5 \mathrm{~mm}$ (mid-section of the specimen), all the composite specimen exhibit fairly constant impact resistance of around $1600 \mathrm{~N}$. Thus, in the compression region, SMA addition does not contribute much to impact resistance; however, with traverse of the indenter below the neutral axis (i.e., tensile region), SMA tends to influence the impact resistance, depending on the weight percentage and temperature of the impact testing. As observed in figure 7, up to $1.5 \mathrm{~mm}$ (mid-section of the laminate), the laminate experiences compression load; not much of this contributed to impact resistance by SMA reinforcement can be seen. While traversing below neutral axis (mid-section of the laminate), the SMA strips will experience pseudo-elastic deformation (loading of martensite phase) and loading of austenite phase (transformed at high temperature). With testing temperature of $303 \mathrm{~K}$, the SMA short strips retain martensite phase undergoing pseudo-elastic deformation (mechanical loading). This results in enhanced resistance to impact loading at higher weight percentage of SMA (4 and 6\%). With increasing temperature at 333 and $363 \mathrm{~K}$, due to transformation to austenite phase, a drop in impact resistance can be observed (i.e., the specimen of $6 \mathrm{wt} \%$ SMA-reinforced composite at test temperature of $303 \mathrm{~K}$, exhibited maximum resistance to impact loading). Referring to the illustration of penetrationdependent impact resistance, it is observed that up to $3 \mathrm{~mm}$, the thickness of the test specimen, impact resistance is in the range of $2000-2800 \mathrm{~N}$ at $303 \mathrm{~K}$, around $2000-2400 \mathrm{~N}$ at

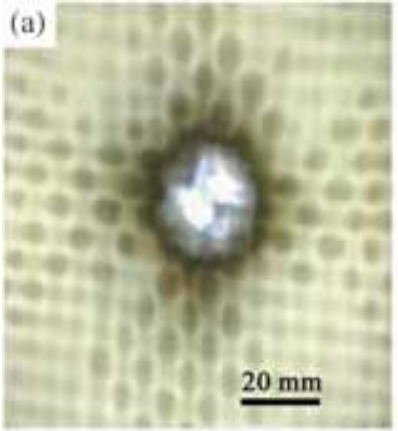

Plain GFRP

$V=2.80 \mathrm{~ms}^{-1}, T=303 \mathrm{~K}$

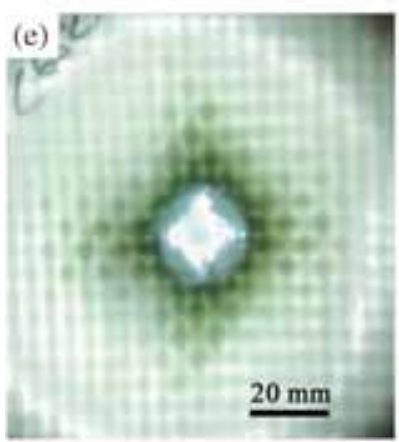

Plain GFRP

$V=2.80 \mathrm{~ms}^{-1}, T=333 \mathrm{~K}$

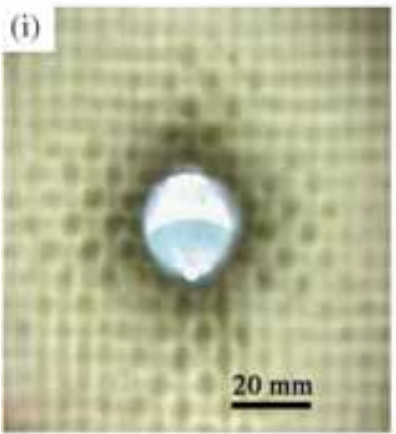

Plain GFRP

$V=2.80 \mathrm{~ms}^{-1}, T=363 \mathrm{~K}$

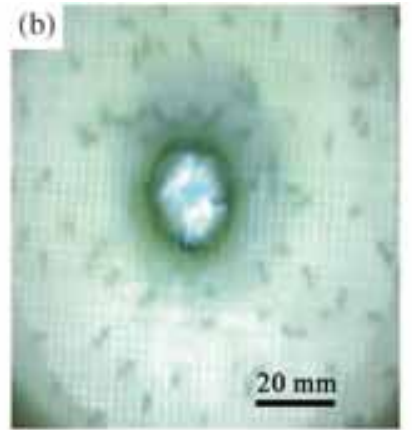

GFRP with 2 wt $\%$ of SMA $V=2.80 \mathrm{~ms}^{-1}, T=303 \mathrm{~K}$

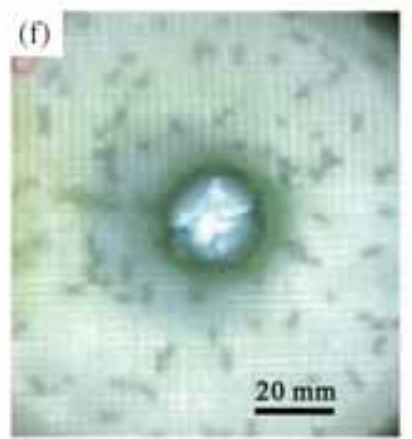

GFRP with 2 wt $\%$ of SMA $V=2.80 \mathrm{~ms}^{-1}, T=333 \mathrm{~K}$

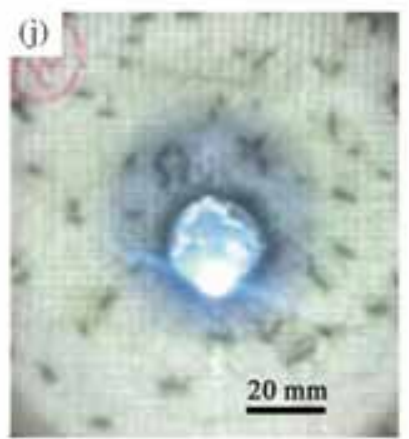

GFRP with 2 wt $\%$ of SMA $V=2.80 \mathrm{~ms}^{-1}, T=363 \mathrm{~K}$

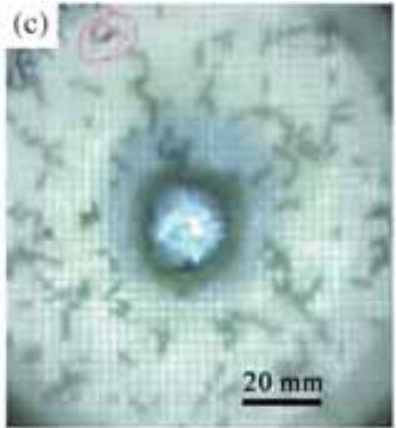

GFRP with 4 wt $\%$ of SMA $V=2.80 \mathrm{~ms}^{-1}, T=303 \mathrm{~K}$

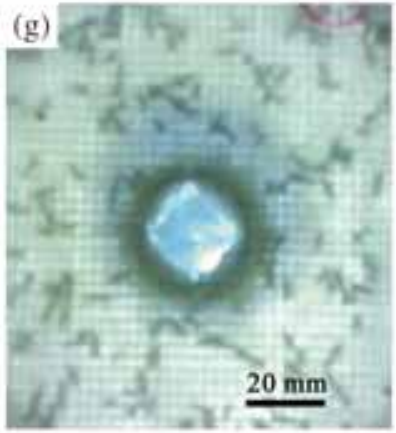

GFRP with 4 wt $\%$ of SMA $V=2.80 \mathrm{~ms}^{-1}, T=333 \mathrm{~K}$

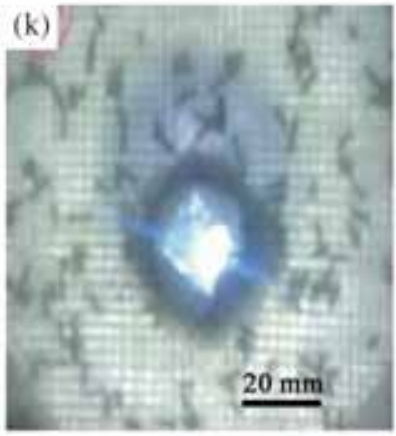

GFRP with 4 wt $\%$ of SMA $V=2.80 \mathrm{~ms}^{-1}, T=363 \mathrm{~K}$

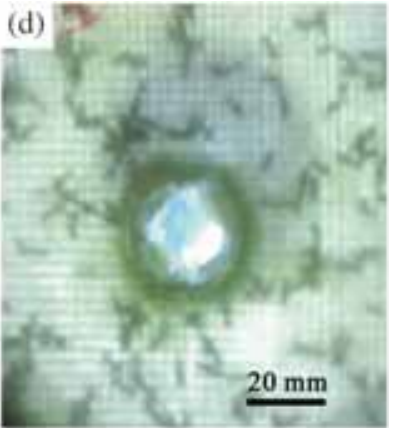

GFRP with 6 wt $\%$ of SMA $V=2.80 \mathrm{~ms}^{-1}, T=303 \mathrm{~K}$

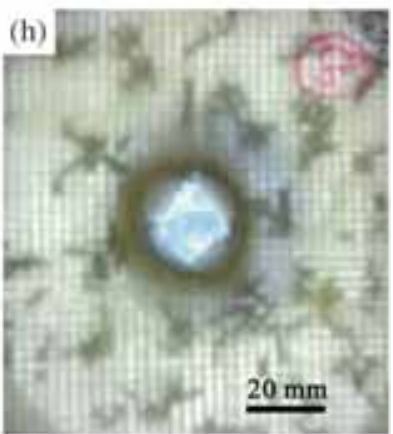

GFRP with 6 wt $\%$ of SMA $V=2.80 \mathrm{~ms}^{-1}, T=333 \mathrm{~K}$

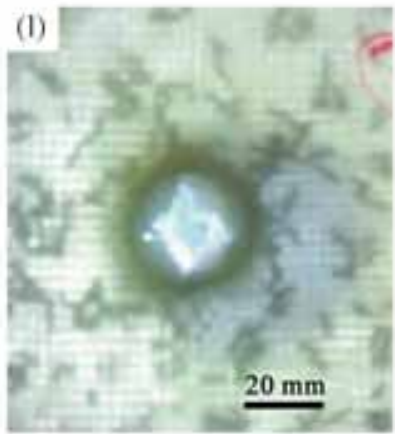

GFRP with 6 wt $\%$ of SMA $V=2.80 \mathrm{~ms}^{-1}, T=363 \mathrm{~K}$

Figure 9. Typical macrograph of indented zone over peeling-off region with SMA wire reinforced at $0.75 t$. 
$333 \mathrm{~K}$ and $1800-2100 \mathrm{~N}$ at $363 \mathrm{~K}$. Thus, it can be inferred that the composite specimen exhibits highest impact resistance with $6 \mathrm{wt} \%$ of SMA at $303 \mathrm{~K}$ of testing temperature. This is attributable to enhanced resistance to delamination at $303 \mathrm{~K}$ compared to other testing temperatures.

3.3c Energy vs. deflection (penetration depth): Typical monitored variation of energy absorbed with indenter traverse (penetration depth) is illustrated in figure 8. It shows the significance of SMA reinforcement on energy absorption. Addition of $6 \mathrm{wt} \%$ SMA to the GFRP composites enhances the energy absorption at all temperatures of investigation. Also with increase in temperature, a rise in energy absorption is observed, which is attributed to SMA exhibiting phase transformation from martensite to austenite. The indenter traverse through the composite specimen unreinforced up to the neutral region, below which the indenter traverse through the composite-reinforced with SMA. Also, with lowest temperature $(303 \mathrm{~K})$, the SMA reinforcement has exhibited pseudo-elastic straining of the martensite, enhanced the strength of the composite, affecting thereby the impact resistance. With increasing temperature, owing to SMA phase transformed from martensite to relatively softer austenitic phase, the overall impact resistance drops down. Referring to the illustration, it is observed that with all testing temperatures, composite reinforced with $6 \mathrm{wt} \%$ of SMA exhibit marginally higher energy absorption.

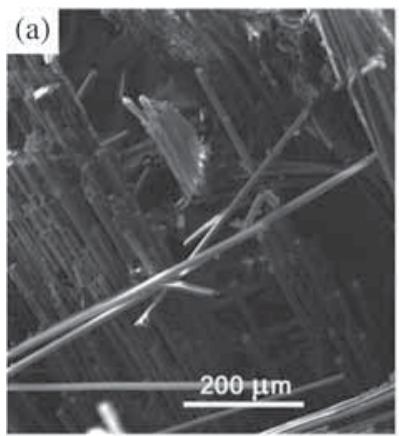

Plain GFRP

$V=2.80 \mathrm{~m} \mathrm{~s}^{-1}, T=303 \mathrm{~K}$

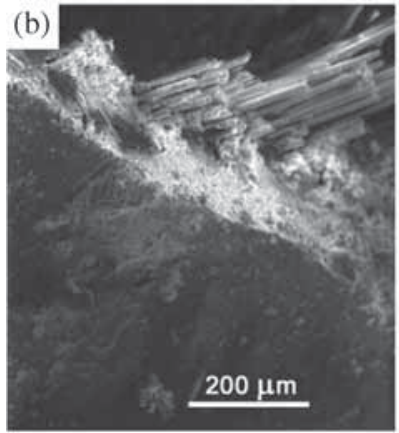

Plain GFRP

$V=2.80 \mathrm{~m} \mathrm{~s}^{-1}, T=333 \mathrm{~K}$

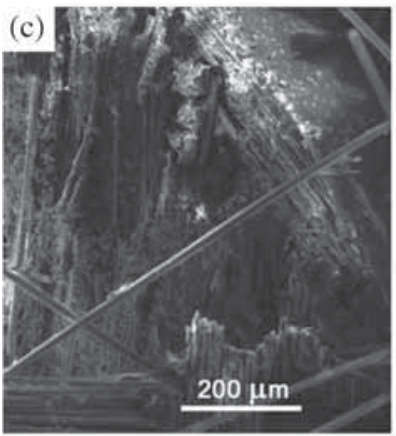

Plain GFRP

$V=2.80 \mathrm{~m} \mathrm{~s}^{-1}, T=363 \mathrm{~K}$

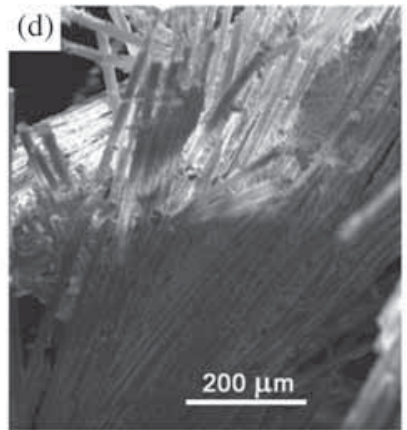

GFRP with 2 wt $\%$ of SMA $V=2.80 \mathrm{~m} \mathrm{~s}^{-1}, T=303 \mathrm{~K}$

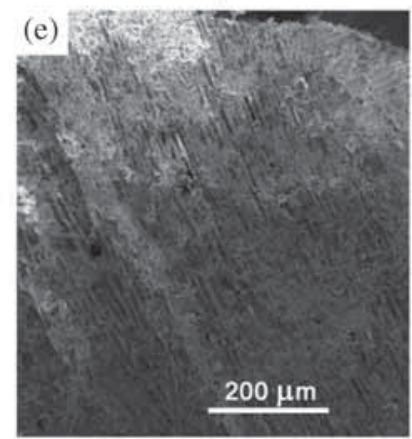

GFRP with 2 wt $\%$ of SMA $V=2.80 \mathrm{~m} \mathrm{~s}^{-1}, T=333 \mathrm{~K}$

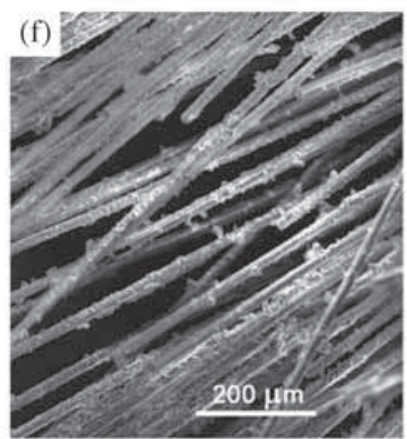

GFRP with $2 \mathrm{wt} \%$ of SMA $V=2.80 \mathrm{~m} \mathrm{~s}^{-1}, T=363 \mathrm{~K}$

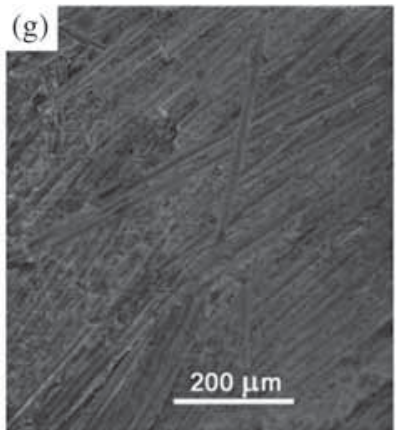

GFRP with 4 wt $\%$ of SMA $V=2.80 \mathrm{~m} \mathrm{~s}^{-1}, T=303 \mathrm{~K}$

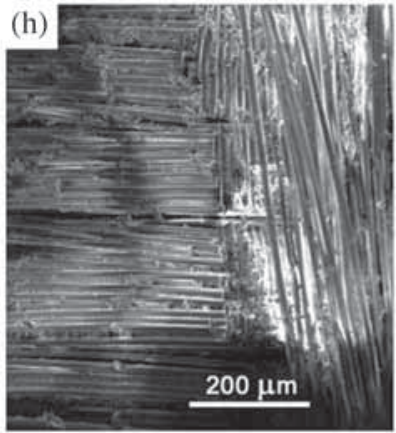

GFRP with $4 \mathrm{wt} \%$ of SMA $V=2.80 \mathrm{~m} \mathrm{~s}^{-1}, T=333 \mathrm{~K}$

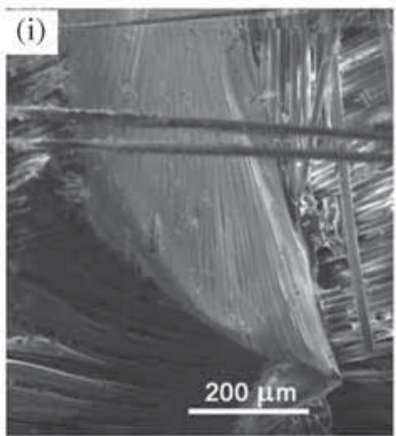

GFRP with 4 wt $\%$ of SMA $V=2.80 \mathrm{~m} \mathrm{~s}^{-1}, T=363 \mathrm{~K}$

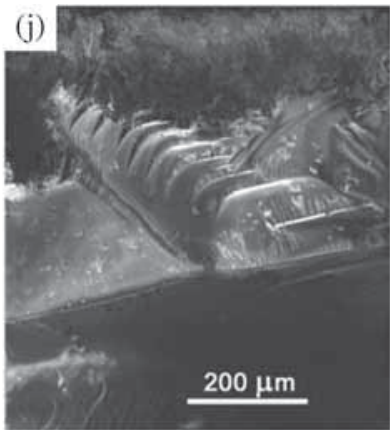

GFRP with $6 \mathrm{wt} \%$ of SMA $V=2.80 \mathrm{~m} \mathrm{~s}^{-1}, T=303 \mathrm{~K}$

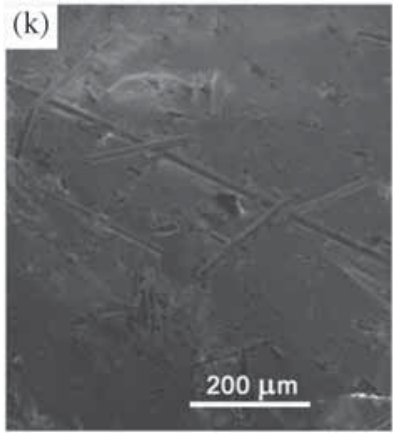

GFRP with $6 \mathrm{wt} \%$ of SMA $V=2.80 \mathrm{~m} \mathrm{~s}^{-1}, T=333 \mathrm{~K}$

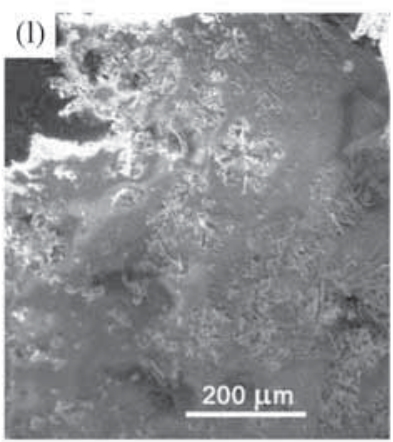

GFRP with $6 \mathrm{wt} \%$ of SMA $V=2.80 \mathrm{~m} \mathrm{~s}^{-1}, T=363 \mathrm{~K}$

Figure 10. Scanning electron micrograph of damaged portion in the peeling-off region with SMA strips placed at $0.75 t$. 
Table 1. Results of low velocity $\left(2.80 \mathrm{~m} \mathrm{~s}^{-1}\right)$ impact on plain GFRP and SMA-reinforced GFRP composites.

\begin{tabular}{lcccc}
\hline $\begin{array}{l}\text { Temperature } \\
(\mathrm{K})\end{array}$ & $\begin{array}{c}\text { Sample (position } \\
\text { of SMA wire and } \\
\text { wt } \%)\end{array}$ & $\begin{array}{c}\text { Peak } \\
\text { force } \\
(\mathrm{N})\end{array}$ & $\begin{array}{c}\text { Absorbed } \\
\text { peak energy } \\
(\mathrm{J})\end{array}$ & $\begin{array}{c}\text { Damage } \\
\text { area }\left(\mathrm{mm}^{2}\right)\end{array}$ \\
\hline 303 & Plain GFRP & 2722 & 25.41 & 639 \\
& $0.75 t, 2 \%$ & 2860 & 22.76 & 510 \\
& $0.75 t, 4 \%$ & 2871 & 21.57 & 492 \\
& $0.75 t, 6 \%$ & 3245 & 22.75 & 485 \\
333 & & & & 650 \\
& Plain GFRP & 2347 & 25.51 & 604 \\
& $0.75 t, 2 \%$ & 2433 & 18.17 & 592 \\
& $0.75 t, 4 \%$ & 2624 & 18.59 & 570 \\
& $0.75 t, 6 \%$ & 3440 & 22.67 & 660 \\
& & & & 563 \\
& Plain GFRP & 2033 & 20.25 & 548 \\
& $0.75 t, 2 \%$ & 2084 & 13.61 & 483 \\
\hline $0.75 t, 4 \%$ & 2107 & 18.98 & \\
& $0.75 t, 6 \%$ & 2459 & 19.72 & \\
\hline
\end{tabular}

\subsection{Damage analysis}

Typical macrograph of the indented zone due to impact of the composite specimen with SMA strip reinforcement embedded at $0.75 t$ of the specimen is illustrated in figure 9 . It is observed that with increasing test temperatures, plain GFRP exhibit enhanced damage. The GFRP composite with $2 \mathrm{wt} \%$ of SMA reinforced, exhibit relatively reduced order of damage. It is also observed that only at $303 \mathrm{~K}$ test temperature, there is a progressive reduction in the damage with increasing SMA wt\%. In the case of $333 \mathrm{~K}$ test temperature, it is observed that the damage is mostly invariant with increasing weight percentage of SMA. With $363 \mathrm{~K}$ test temperature, possibly due to transformation to austenitic phase and consequent reduced peeling-off damage can be observed.

SEM images were taken around the periphery of intended/impacted zone. Typical micrograph of peeled-off region of the composite laminate exposed to drop weight impact under different temperatures are presented in figure 10 . The scanning electron micrographs of peeled-off region with plain GFRP composite at different temperatures are presented in figure $10 \mathrm{a}-\mathrm{c}$. With increasing temperature of the impact, the plain GFRP exhibits only a marginal variation in either impact resistance or impact energy absorption. Due to possible thermal softening of the matrix, the composite expose matrix crazing, fibre breakage and delamination over surface region as shown in figure 10a-c. GFRP composites reinforced with $2 \mathrm{wt} \%$ of SMA addition, exhibit a different micrograph over the peeled-off region as shown in figure 10d-f. From these micrographs, it is observed that these specimens exhibited with lesser damage compared to plain GFRP micrograph. Mostly, the specimens depict matrix loosing/spalling exposing the section of the fibre reinforcement (over the surface region). GFRP composites with $4 \mathrm{wt} \%$ of SMA reinforcements (embedded at $0.75 \times$ thickness of the specimen) with increasing temperature, possible transformation to austenite could have enhanced the bending stiffness or possible rebounding of the impactor partially, at the

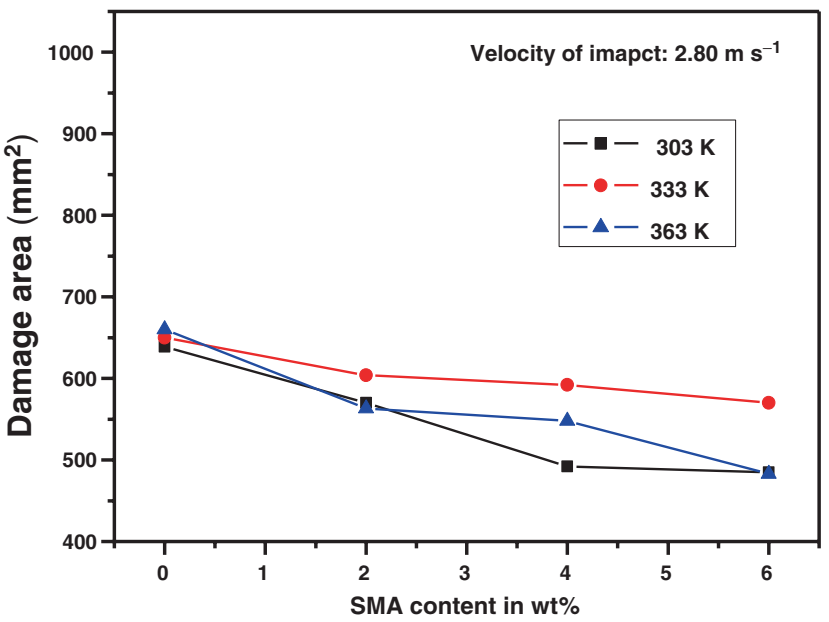

Figure 11. Plot of damage area vs. SMA content.

entry, causing less damage as reflected in SEM images shown in figure $10 \mathrm{~g}-\mathrm{i}$. With increasing wt\% of SMA (6 wt \%)reinforced GFRP composites exhibit improved impact resistance with reduced surface damage. The micrographs of peeled-off region are shown in figure $10 \mathrm{j}-1$ with less damaged microstructure. The dynamic response due to drop weight impact on plain and SMA strip-reinforced GFRP composites is tabulated in table 1 .

\subsection{Parameter influence on damage area}

The variation of damage area of composite specimen subjected to drop weight impact as influenced by SMA strip reinforcement with various temperatures at constant impact velocity is illustrated in figure 11 . The data obtained are average values of three experiments which have less than the standard error limit $(<5 \%)$. It is observed that with increasing SMA content, a reduction in damage area occurs; also a mostly reduced damage can be observed at room temperature 
(303 K). The impact resistance progressively drops down with temperature of impact. However, the damage area varies wider with low and high temperatures compared to medium temperature. This can be attributed to possible deformation (plateau) of heterogeneous nature of the structure due to the presence of SMA in fully martensite/austenite phase.

\section{Conclusion}

From this study, the drop weight impact of the composite specimen with and without SMA strips reinforcement under different temperatures, the following conclusions are drawn.

1. The drop weight impact is associated with transverse through the specimen thickness and also with fluffed off projection at the exit, which varies depending on the temperature and SMA reinforcements.

2. It is observed that as a whole, with increasing weight percentage of SMA (6 wt\%), the SMA-reinforced GFRP composites exhibit increased impact resistance. The impact resistance drops down with rise in impact temperature could be attributed to reduced tendency to rebound with increasing temperature.

3. The impact resistance (due to drop weight) has been measured and found that up to neutral axis all the composites exhibit same impact resistance; significance of SMA addition has been observed only in the tensile region and exit fluffing region.

4. It is observed that increasing addition of SMA content (6 wt $\%)$ enhanced the impact resistance of GFRP composites.

5. The impact resistance of composites dropped down progressively with increasing test temperatures.

\section{Acknowledgements}

Pazhanivel is grateful to Prof BTN Sridhar, Anna University, for the fruitful discussion and encouragement. He also acknowledges the help rendered by Mr B Balaji for his help in carrying out the experiments.

\section{References}

[1] Abrate S 1991 Appl. Mech. Rev. 44155

[2] Kang K W and Kim K 2006 Composite Part A 371451

[3] Zhang R-X, Ni Q-Q, Natsuki T and Iwamoto M 2007 Compos. Struct. 7990

[4] Roh H and Kim H 2002 Compos. Struct. 56175

[5] Tsoi K A, Stalmans R, Schrooten J, Wevers M and Mai Y W 2003 Mater. Sci. Eng. A 342207

[6] Karasek M L, Strait H L, Amateau M F and Runt P 1995 J. Camps Technol. Res. 17111

[7] Bibo G A, Leicy D, Hogg P and Kemp M 1994 Compos. 25 414

[8] Ibekwe S, Mensah P F, Li G, Pang S S and Stubblefield M A 2007 Compos. Struct. 7912

[9] Kang K W, Kim H J and Kim J K 2007 J. Mech. Sci. Technol. 211682

[10] Metin Sayer, Numan B Bektas, Ersin Demir and Hasan Callioglu 2012 Composite Part B $\mathbf{4 3} 2152$

[11] Amin Salehi-Khojin, Mohammad Mahinfalah, Reza Bashirzadeh and Brian Freeman 2007 J. Compos. Struct. 78 197

[12] Amal A M Badawy 2012 Ain Shams Eng. J. 3105

[13] Xu Y, Otsuka K, Nagai H, Yoshida H, Asai M and Kishi T 2003 Scripta Mater. 49587

[14] Ki-Weon Kang and Jung-Kyu Kim 2009 Compos. Struct. 88 455

[15] Pazhanivel K, Bhaskar G B, Arunachalam S, Hariharan V and Elayaperumal A 2012 Appl. Mech. Mater. 632 110-116

[16] Pazhanivel K, Bhaskar G B, Elayaperumal A, Anandan P and Arunachalam S 2015 Arab. J. Sci. Eng. 401111

[17] Raghavan J, Trevor Berthikerkie, Shawna Boyko, Mike Kupriyanav, Rajabakse N and Ben Yu 2010 Composite Part B 41214

[18] Lau K-T, Ling H-Y and Zhou L-M 2004 Smart Mater. Struct. 13364

[19] Ni Q-Q, Zhang R-X, Natsuki T and Iwamoto M 2007 Compos. Struct. 79501 